\title{
Manufacturer's pricing strategies in cooperative and non-cooperative advertising supply chain under retail competition
}

\author{
B. C. Giri* and S. Sharma
}

Department of Mathematics, Jadavpur University, Kolkata-700032, India

\section{CH R O N I C L E}

\begin{tabular}{l}
\hline Article history: \\
Received November 22013 \\
Received in Revised Format \\
March 172014 \\
Accepted March 182014 \\
Available online \\
March 19 2014 \\
\hline Keywords: \\
Supply chain \\
Manufacturer \\
Retailer \\
Advertisement \\
Stackelberg
\end{tabular}
\begin{abstract}
A B S T R A C T
This article studies the manufacturer's pricing strategy in a supply chain with a single manufacturer and two competing retailers. The manufacturer, as a Stackelberg leader specifies wholesale prices to two retailers who face advertisement dependent demand. Based on this gaming structure, two mathematical models are developed - the cooperative advertising model where manufacturer shares a fraction of retailers' advertising costs and the non-cooperative advertising model where manufacturer does not share any retailer's advertising expenses. The optimal strategies of the manufacturer and retailers are determined and a numerical example is taken to illustrate the theoretical results derived. We show that cooperative advertising policy is beneficial not only for the participating entities but also for the entire supply chain.
\end{abstract}

\section{Introduction}

The study of consumer behaviour explores that besides price, there are other factors such as product quality, brand image and service which have significant influence on consumers' purchasing decisions and hence market demand. Advertising is a very common communication tool used by business organisations to notify consumers about their products and services. To inform consumers regarding a commercial offering, a firm has to invest money for advertisement via various traditional mass media such as newspaper, magazines, television channels, radio as well as outdoor advertisement such as distribution of leaflets among people or displaying messages in sign boards or banners, etc. Some new media such as direct mail, social networking sites, text messages are also used in promotional campaign. With the objective of persuading consumers to buy, advertising performs two major functions. Firstly, it provides valuable information to consumers regarding product and enable them to make rationale choices by reducing informational product differentiation. Secondly, it persuades consumers by means of intangible and/or psychic differentiators and creates differentiation among

$*$ Corresponding author.

E-mail: bcgiri.jumath@gmail.com (B. C. Giri)

(C) 2014 Growing Science Ltd. All rights reserved. doi: $10.5267 /$ j.jijiec.2014.3.001 
products (Huang et al., 2012). Since advertising significantly impacts consumers' purchasing behavior and thus demand, firms now-a-days are increasing their advertising expenditures to boost sales and maximize profit.

Cooperative (or co-op) advertising is an interactive scheme or financial agreement between a manufacturer and a retailer in which the retailer initiates and implements a local advertisement and the manufacturer pays part of the cost. It is often used in consumer goods industry and it plays an important role in marketing strategy of many companies. The percentage of retailer's advertising cost which the manufacturer agrees to pay is commonly referred to as manufacturer's 'participation rate' (Bergen \& John, 1997). Though both manufacturers and retailer make advertising efforts to increase sales at the retail level, their outlooks are different. The manufacturer's national advertising is intended to influence potential customers to consider brand and increase brand image and awareness, while retailer's local advertising is intended to bring potential customers to the stage of desire and action, and give an immediate reason to buy (Huang \& Li, 2001). Manufacturer uses co-op advertising to strengthen the image of the brand and motivate immediate sales at the retail level (Hutchins, 1953). In the absence of co-op advertising, a retailer may advertise for the manufacturer's product to increase its sales, but it might not do to that extent which the manufacturer prefers. Therefore, manufacturer sometimes provides financial assistance to the retailer to increase its advertising efforts. According to Brennan (1988), in the personal computer industry, IBM offers a 50-50 split of advertising costs with retailers while Apple pays $75 \%$ of the media cost. Nagler (2006) reports that total expenditures on co-op advertising in the United States in 2000 were estimated at $\$ 15$ billion; an approximately four-fold increase in real terms compared with $\$ 900$ million in 1970 . The overall significance and growing trend in co-op advertising suggest the need for more research on this topic.

The research on co-op advertising can be broadly categorized under two groups. In the first group, researchers solely concentrate their analyses on advertising. Berger (1972) was the first to study co-op advertising between a manufacturer and a retailer quantitatively. Dant and Berger (1996) used co-op advertising in the context of franchising. Roslow et al. (1993) studied co-op advertising in a supply chain and showed that sharing of advertising investment leads to improved profit of the whole supply chain. More studies on co-op advertising can be found in the articles contributed by Karray and Zaccour (2006), Jorgensen et al. (2000, 2003) and Jorgensen and Zaccour (2003). Motivated by the rise of retailing power from manufacturer to retailer in recent years, Huang and Li (2001) used game-theory to study co-op advertising models in the context of different relationships between the manufacturer and the retailer. They relaxed the leader-follower relationship between a manufacturer and a retailer and considered the simultaneous move game. The equilibrium attained in the process is termed as Nash equilibrium. They showed that if the profit ratio of the manufacturer and the retailer is relatively low then the local advertising expenditure is lower at Nash equilibrium than at Stackelberg equilibrium; otherwise, it is higher at Nash equilibrium than at Stackelberg equilibrium. Similar approaches but with slightly different demand functions were considered by Li et al. (2002), Huang et al. (2002) and Huang and $\mathrm{Li}(2005)$.

The other group of researchers, e.g., Bergen and John (1997), Kim and Staelin (1997), and Karray and Zaccour (2007) considered price as decision variable. Yue et al. (2006) considered cooperative advertising in a two-level manufacturer-retailer supply chain where demand is price- sensitive. They determined optimal decisions of the manufacturer and the retailer in both cooperative and noncooperative cases when manufacturer provides a price discount directly to the customers. Xie and Neyret (2009) discussed co-op advertising and pricing strategies in a manufacturer-retailer channel. They considered four different models which are based on three non-cooperative games (i.e. Nash, retailer-Stackelberg and manufacturer-Stackelberg) and one cooperative game. Xie and Wei (2009) identified the optimal equilibrium pricing and co-op advertising strategies in channel coordination between a manufacturer and a retailer. More articles that deal with pricing and advertising decisions can be found in Szmerekovsky and Zhang (2009), Yan (2010), SeyedEsfahani et al. (2011) and others. 
Recently, Kunter (2012) analyzed a royalty payment contract for coordination of a manufacturerretailer channel where consumer demand is simultaneously affected by retail price and by manufacturer's and retailer's marketing efforts. For a more comprehensive review of the literature on co-op advertising in supply chain, readers can be referred to the article contributed by Aust and Busher (2014).

This paper investigates the effects of manufacturer's different pricing strategies in a supply chain with one manufacturer and two competing retailers. The manufacturer as a Stackelberg leader specifies wholesale prices to retailers who face advertising dependent demand. Depending upon the prevailing market situations and retailers' sales cost information, the manufacturer may chose different pricing strategy. Chen et al. (2012) examined manufacturer's pricing strategies in a two-level supply chain with one manufacturer and two competing retailers who face warranty period-dependent demand. The literature on co-op advertising in supply chain dealing with retail competition is sparse, with some exceptions such as He et al. (2011) and Wang et al. (2011). Mirzaee et al. (2012) discussed supply chain coordination in a two-level supply chain with one manufacturer and two competing retailers under advertising dependent demand. These articles did not consider the impact of pricing on the manufacturer's and retailers' as well as whole supply chain's performances. The present study focuses on the evaluation of manufacturer's pricing strategy in conjunction with retailers' gaming interactions and its likely impact on supply chain's performance. The results of this study provide guidelines to both the manufacturer and retailers who face similar challenges.

The remainder of this article is organized as follows: Assumptions and model description are presented in Section 2. In Section 3, cooperative advertising model is formulated under different pricing strategies proposed by the manufacturer. Section 4 studies the impact of the manufacturer's different pricing strategies on the members' as well as the entire supply chain's performances. Section 5 discusses the non-cooperative model where manufacturer does not participate in cooperative advertising. Using a numerical example, theoretical results are verified in Section 6. In Section 7, we summarize the main findings of our research and indicate several possible extensions and follow-up issues.

\section{Assumptions and model description}

We consider a two-echelon supply chain where one manufacturer sells its product through two competing retailers. The manufacturer is the Stackelberg leader and the retailers are the followers. Let the unit retail price be $p$ and the unit manufacturing cost be $c$. The two retailers have different sales efficiencies and hence have different sales cost. Let the retailer $i$ 's unit sales cost be $s_{i}(i=1,2)$. Without any loss of generality, we assume that $s_{1}<s_{2}$. We assume that the market demand is influenced by the advertising expenditure incurred by the retailers in promoting the product. Further, the price differentiation between retailers is insignificant to the customers at the time of purchasing. The two retailers compete with each other in advertising. To each retailer, the demand increases with its own advertising while it decreases with the advertising done by his/her opponent. Similar to other conventional demand function (defined by Arcelus et al. 2012, Wu et al. 2012), we define retailer $i$ 's demand by $D\left(I_{i}\right)=\alpha+\beta \sqrt{I_{i}}-\gamma \sqrt{I_{j}}, \quad(i=1,2$ and $j=3-i)$. Here, $I_{i}$ denotes retailer $i$ 's advertising expenditure, $\alpha$ denotes the primary demand of retailer $i, \beta$ represents consumers' sensitivity to advertising done by retailer $i$, while $\gamma$ denotes competitive factor. The linear and symmetrical demand function represents a situation in which two retailers have equal competing power in a duopolistic market place. We assume $\gamma<\beta$, which ensures that the response functions are negatively sloped and the Nash equilibrium exists. This appears reasonable since sales are relatively more sensitive to retailer's own advertising than the advertising done by the competing retailer. This demand pattern has often been used in marketing research (see Ingene and Parry 1995; Padmanabhan and Png, 1997) and in some economics literature (see Singh and Vives 1984; Vives, 1984, 1985). 


\section{Model I: Cooperative advertising model}

We assume that the manufacturer shares a fraction $(t)$ of each retailer's advertising allowances. The manufacturer sets the same proportion of advertising allowance to two competing retailers. The Robinson-Patman Act (1936) requires a manufacturer to treat all competitive retailers equally (proportionately) with respect to advertising allowances (Wang et al., 2011). We assume that the manufacturer considers three pricing options in deciding wholesale prices for the retailers: (1) the same wholesale price for each retailer, while disregarding their differences with regard to sales cost (strategy 1); (2) different wholesale prices to each retailer on the basis of their sales costs (strategy 2); and (3) the same wholesale price to each retailer according to the average sales cost of the industry (strategy 3 ).

\subsection{Case1: Manufacturer's pricing strategy 1}

With manufacturer's pricing strategy 1 , the sequence of events is as follows: the manufacturer first sets a common wholesale price $w_{1}$ according to retailer's sales cost $s_{i}$ 's, $i=1,2$. In response, the retailers observe $w_{1}$ and follow Nash equilibrium to determine their optimal advertising expenditures.

\subsubsection{The retailer's problem}

The retailer $i$ faces the problem of determining advertising expenditure $I_{1 i}$ which maximizes his/her profit. Retailer $i^{\prime} s$ profit is given by

$$
T P_{1 i}^{r}=\left(p-w_{1}-s_{i}\right)\left(\alpha+\beta \sqrt{I_{1 i}}-\gamma \sqrt{I_{1 j}}\right)-(1-t) I_{1 i}, i=1,2 \text { and } j=3-i .
$$

Proposition 1. For the pricing strategy 1 of the manufacturer, the retailers 1 and 2's optimal advertising expenditures are given by

$$
I_{11}^{*}=\frac{\left(p-w_{1}-s_{1}\right)^{2} \beta^{2}}{4(1-t)^{2}} \text { and } I_{12}^{*}=\frac{\left(p-w_{1}-s_{2}\right)^{2} \beta^{2}}{4(1-t)^{2}}, \text { respectively. }
$$

Proof: From (1), we have

$$
\frac{d^{2} T P_{1 i}^{r}\left(I_{1 i}\right)}{d^{2} I_{1 i}}=-\frac{\left(p-w_{1}-s_{i}\right) \beta}{4 I_{1 i}^{3 / 2}}<0,
$$

implying that $T P_{1 i}^{r}\left(I_{1 i}\right)$ is concave in $I_{1 i}$. Solving $\frac{d T P_{1 i}^{r}\left(I_{1 i}\right)}{d I_{1 i}}=0$, we obtain $I_{11}^{*}=\frac{\left(p-w_{1}-s_{1}\right)^{2} \beta^{2}}{4(1-t)^{2}}$ and $I_{12}^{*}=\frac{\left(p-w_{1}-s_{2}\right)^{2} \beta^{2}}{4(1-t)^{2}}$. This completes the proof.

Proposition 1 indicates that the retailers' optimal advertising expenditures increase as the manufacturer's participation rate for subsidizing retailers' advertising costs increases. Further, we have $I_{11}^{*}>I_{12}^{*}$ as $s_{1}<s_{2}$. Substituting the values of $I_{11}^{*}$ and $I_{12}^{*}$ in (1), we get the retailer 1 's optimal profit as

$$
T P_{11}^{r}\left(I_{11}^{*}\right)=\left(p-w_{1}-s_{1}\right)\left[\alpha+\frac{\beta^{2}\left(p-w_{1}-s_{1}\right)}{4(1-t)}-\frac{\beta \gamma\left(p-w_{1}-s_{2}\right)}{2(1-t)}\right]
$$

and retailer 2's optimal profit as

$$
T P_{12}^{r}\left(I_{12}^{*}\right)=\left(p-w_{1}-s_{2}\right)\left[\alpha+\frac{\beta^{2}\left(p-w_{1}-s_{2}\right)}{4(1-t)}-\frac{\beta \gamma\left(p-w_{1}-s_{1}\right)}{2(1-t)}\right]
$$


Proposition 2. For pricing strategy 1 of the manufacturer, retailer 1 gains more profit than retailer 2.

Proof: From Eq. (2) and Eq. (3), we obtain

$$
\begin{aligned}
T P_{11}^{r}\left(I_{11}^{*}\right)-T P_{12}^{r}\left(I_{12}^{*}\right) & =\alpha\left[\left(p-w_{1}-s_{1}\right)-\left(p-w_{1}-s_{2}\right)\right]+\frac{\beta^{2}}{4(1-t)}\left[\left(p-w_{1}-s_{1}\right)^{2}-\left(p-w_{1}-s_{2}\right)^{2}\right] \\
& =\left(s_{2}-s_{1}\right)\left[\alpha+\frac{\beta^{2}}{4(1-t)}\left(\left(p-w_{3}-s_{1}\right)+\left(p-w_{3}-s_{2}\right)\right)\right]>0,
\end{aligned}
$$

since $s_{2}>s_{1}$ and $\left(p-w_{3}-s_{1}\right)>0$ and $\left(p-w_{3}-s_{2}\right)>0$. Thus, $T P_{11}^{r}\left(I_{11}^{*}\right)>T P_{12}^{r}\left(I_{12}^{*}\right)$ which means that for the manufacturer's pricing strategy 1 , retailer 1 gains higher profit than retailer 2 . This completes the proof.

\subsubsection{The manufacturer's problem}

The manufacturer faces the issue of determining the wholesale price which maximizes his/her profit. The manufacturer's profit is given by

$$
T P_{1}^{m}\left(w_{1}\right)=\sum_{i=1}^{2}\left[\left(w_{1}-c\right)\left(\alpha+\beta \sqrt{I_{1 i}^{*}}-\gamma \sqrt{I_{1 j}^{*}}\right)\right]-t\left(I_{11}^{*}+I_{12}^{*}\right), j=3-i .
$$

Substituting the values of $I_{11}^{*}$ and $I_{12}^{*}$ given in Proposition 1, the manufacturer's profit can be written as

$$
T P_{1}^{m}\left(w_{1}\right)=\left(w_{1}-c\right)\left[2 \alpha+\frac{\beta(\beta-\gamma)}{2(1-t)}\left(\left(p-w_{1}-s_{1}\right)+\left(p-w_{1}-s_{2}\right)\right)\right]-\frac{t \beta^{2}}{4(1-t)^{2}}\left[\left(p-w_{1}-s_{1}\right)^{2}+\left(p-w_{1}-s_{2}\right)^{2}\right]
$$

The manufacturer's optimal wholesale price can be obtained as given in the following proposition.

Proposition 3. For the pricing strategy 1, the manufacturer's optimal wholesale price is given by

$$
w_{1}^{*}=\frac{\frac{4 \alpha}{\beta}+\frac{\left(p-s_{1}\right) t \beta}{(1-t)^{2}}+\frac{\left(p-s_{2}\right) t \beta}{(1-t)^{2}}+\frac{\beta-\gamma}{1-t}\left(2(p+c)-s_{1}-s_{2}\right)}{\frac{2 t \beta}{(1-t)^{2}}+\frac{4(\beta-\gamma)}{(1-t)}}
$$

Proof: From Eq. (5), we have

$$
\begin{aligned}
& \frac{d T P_{1}^{m}}{d w_{1}}=2 \alpha+\frac{\beta(\beta-\gamma)}{2(1-t)}\left[\left(p-w_{1}-s_{1}\right)+\left(p-w_{1}-s_{2}\right)-2\left(w_{1}-c\right)\right]+\frac{t \beta^{2}}{2(1-t)^{2}}\left[\left(p-w_{1}-s_{1}\right)+\left(p-w_{1}-s_{2}\right)\right] \\
& \frac{d^{2} T P_{1}^{m}}{d w_{1}^{2}}=-\frac{t \beta^{2}}{(1-t)^{2}}-\frac{2 \beta(\beta-\gamma)}{1-t}<0
\end{aligned}
$$

Therefore, $T P_{1}^{m}\left(w_{1}\right)$ is concave in $w_{1}$. Solving $\frac{d T P_{1}^{m}}{d w_{1}}=0$, we obtain after some calculations

$$
w_{1}^{*}=\frac{\frac{4 \alpha}{\beta}+\frac{\left(p-s_{1}\right) t \beta}{(1-t)^{2}}+\frac{\left(p-s_{2}\right) t \beta}{(1-t)^{2}}+\frac{\beta-\gamma}{1-t}\left(2(p+c)-s_{1}-s_{2}\right)}{\frac{2 t \beta}{(1-t)^{2}}+\frac{4(\beta-\gamma)}{(1-t)}}
$$

This completes the proof.

From Eq. (1) and Eq. (4) and from Propositions 1 and 3, we obtain the profit of the entire supply chain as

$$
\begin{aligned}
& T P_{1}^{w}=T P_{11}^{r}\left(I_{11}^{*}\right)+T P_{12}^{r}\left(I_{12}^{*}\right)+T P_{1}^{m}\left(w_{1}^{*}\right) \\
& =\left(p-c-s_{1}\right)\left(\alpha+\beta \sqrt{I_{11}^{*}}-\gamma \sqrt{I_{12}^{*}}\right)+\left(p-c-s_{2}\right)\left(\alpha+\beta \sqrt{I_{12}^{*}}-\gamma \sqrt{I_{11}^{*}}\right)-I_{11}^{*}-I_{12}^{*}
\end{aligned}
$$




\subsection{Case 2: Manufacturer's pricing strategy 2}

With manufacturer's pricing strategy 2 , the sequence of events is as follows: the manufacturer first sets different wholesale prices $w_{21}$ and $w_{22}$ to retailers 1 and 2, respectively, according to their different sales costs $s_{1}$ and $s_{2}$. Then the retailers observe $w_{2 i}, i=1,2$ and follow Nash's equilibrium to determine their optimal advertising expenditures.

\subsubsection{The retailer's problem}

The retailer's problem is to determine the advertising expense that maximizes his/her profit. The retailer's profit is given by

$$
T P_{2 i}^{r}\left(I_{2 i}\right)=\left(p-w_{2 i}-s_{i}\right)\left(\alpha+\beta \sqrt{I_{2 i}}-\gamma \sqrt{I_{2 j}}\right)-(1-t) I_{2 i}, i=1,2 \text { and } j=3-i
$$

Proposition 4. For the pricing strategy 2 of the manufacturer, the retailers 1 and 2 's optimal advertising expenditures are

$$
I_{21}^{*}=\frac{\left(p-w_{21}-s_{1}\right)^{2} \beta^{2}}{4(1-t)^{2}} \text { and } I_{22}^{*}=\frac{\left(p-w_{22}-s_{2}\right)^{2} \beta^{2}}{4(1-t)^{2}} \text {, respectively. }
$$

Proof: The proof is omitted as it is similar to that given in Proposition 1.

Substituting the values of $I_{21}^{*}$ and $I_{22}^{*}$ in Eq. (9), the retailer 1's optimal profit can be derived as

$$
T P_{21}^{r}\left(I_{21}^{*}\right)=\left(p-w_{21}-s_{1}\right)\left[\alpha+\frac{\beta^{2}\left(p-w_{21}-s_{1}\right)}{4(1-t)}-\frac{\beta \gamma\left(p-w_{22}-s_{2}\right)}{2(1-t)}\right]
$$

and the retailer 2's optimal profit as

$$
T P_{22}^{r}\left(I_{22}^{*}\right)=\left(p-w_{22}-s_{2}\right)\left[\alpha+\frac{\beta^{2}\left(p-w_{22}-s_{2}\right)}{4(1-t)}-\frac{\beta \gamma\left(p-w_{21}-s_{1}\right)}{2(1-t)}\right]
$$

\subsubsection{The manufacturer's problem}

The manufacturer's problem is to select different wholesale prices $w_{2 i}, i=1,2$ which maximize his/her profit. The manufacturer's profit is given by

$$
T P_{2}^{m}\left(w_{21}, w_{22}\right)=\sum_{i=1}^{2}\left(w_{2 i}-c\right)\left(\alpha+\beta \sqrt{I_{2 i}^{*}}-\gamma \sqrt{I_{2 j}^{*}}\right)-t\left(I_{21}^{*}+I_{22}^{*}\right), j=3-i
$$

Substituting the values of $I_{21}^{*}$ and $I_{22}^{*}$ from Proposition 4, we obtain

$$
\begin{aligned}
T P_{2}^{m}\left(w_{21}, w_{22}\right) & =\left(w_{21}-c\right)\left[\alpha+\frac{\beta^{2}\left(p-w_{21}-s_{1}\right)}{2(1-t)}-\frac{\beta \gamma\left(p-w_{22}-s_{2}\right)}{2(1-t)}\right]+\left(w_{22}-c\right)\left[\alpha+\frac{\beta^{2}\left(p-w_{22}-s_{2}\right)}{2(1-t)}-\frac{\beta \gamma\left(p-w_{21}-s_{1}\right)}{2(1-t)}\right] \\
& -\frac{t \beta^{2}}{4(1-t)^{2}}\left[\left(p-w_{21}-s_{1}\right)^{2}+\left(p-w_{22}-s_{2}\right)^{2}\right]
\end{aligned}
$$

With regard to the manufacturer's optimal wholesale prices, we state the following proposition.

Proposition 5. For the pricing strategy 2, the manufacturer's optimal wholesale prices are

$$
w_{21}^{*}=\frac{\left(\frac{\beta^{2}}{1-t}+\frac{t \beta^{2}}{2(1-t)^{2}}\right)\left[\left(\frac{\beta^{2}}{1-t}+\frac{t \beta^{2}}{2(1-t)^{2}}\right) X+\frac{\beta \gamma}{(1-t)} Y\right]}{\frac{\beta \gamma}{(1-t)}\left[\left(\frac{\beta^{2}}{(1-t)}+\frac{t \beta^{2}}{2(1-t)^{2}}\right)^{2}-\frac{\beta^{2} \gamma^{2}}{(1-t)^{2}}\right]}-\frac{(1-t) X}{\beta \gamma}
$$

and 


$$
w_{22}^{*}=\frac{\left[\left(\frac{\beta^{2}}{1-t}+\frac{t \beta^{2}}{2(1-t)^{2}}\right) X+\frac{\beta \gamma}{(1-t)} Y\right]}{\left(\frac{\beta^{2}}{(1-t)}+\frac{t \beta^{2}}{2(1-t)^{2}}\right)^{2}-\frac{\beta^{2} \gamma^{2}}{(1-t)^{2}}}
$$

where

$$
\begin{aligned}
& X=\alpha+\frac{\beta^{2}}{2(1-t)}\left(p+c-s_{2}\right)+\frac{t \beta^{2}}{2(1-t)^{2}}\left(p-s_{2}\right)-\frac{\beta \gamma}{2(1-t)}\left(p+c-s_{1}\right) \\
& Y=\alpha+\frac{\beta^{2}}{2(1-t)}\left(p+c-s_{1}\right)+\frac{t \beta^{2}}{2(1-t)^{2}}\left(p-s_{1}\right)-\frac{\beta \gamma}{2(1-t)}\left(p+c-s_{2}\right)
\end{aligned}
$$

Proof: The proof is given in Appendix.

Corollary 1. $w_{21}^{*}>w_{22}^{*}$ and $I_{21}^{*}>I_{22}^{*}$.

Proof: From Proposition 5, we have after simplifying, $w_{21}^{*}-w_{22}^{*}=\frac{\left(s_{2}-s_{1}\right)[\beta+(1-t) \gamma]}{(2-t) \beta+2(1-t) \gamma}$. Since, $s_{2}>s_{1}$, we obtain $w_{21}^{*}>w_{22}^{*}$. Then we have $w_{22}^{*}-w_{21}^{*}+s_{2}-s_{1}=\frac{\left(s_{2}-s_{1}\right)(1-t)(\beta+\gamma)}{(2-t) \beta+2(1-t) \gamma}$.

Next, from Proposition 4, we have

$$
\begin{aligned}
I_{21}^{*}-I_{22}^{*} & =\frac{\beta^{2}}{4(1-t)^{2}}\left[\left(p-w_{21}^{*}-s_{1}\right)^{2}-\left(p-w_{22}^{*}-s_{2}\right)^{2}\right] \\
& =\frac{\beta^{2}}{4(1-t)^{2}}\left[\left(p-w_{21}^{*}-s_{1}\right)+\left(p-w_{22}^{*}-s_{2}\right)\right]\left(w_{22}^{*}-w_{21}^{*}+s_{2}-s_{1}\right) \\
& =\frac{\left(s_{2}-s_{1}\right) \beta^{2}(\beta+\gamma)\left[\left(p-w_{21}^{*}-s_{1}\right)+\left(p-w_{22}^{*}-s_{2}\right)\right]}{4(1-t)[(2-t) \beta+2(1-t) \gamma]}>0 .
\end{aligned}
$$

Since $s_{2}>s_{1}$ and $\left(p-w_{21}^{*}-s_{1}\right)>0,\left(p-w_{22}^{*}-s_{2}\right)>0$. Therefore, we have $I_{21}^{*}>I_{22}^{*}$. This completes the proof.

From the above corollary, we find that the manufacturer charges a greater wholesale price to retailer 1 than retailer 2. Also, we find that retailer 1 incurs a greater advertising expenditure than retailer 2. Thus, from Proposition 1 and Corollary 1, we conclude that retailer 1 spends more than retailer 2 in advertising with both manufacturer's pricing strategies 1 and 2 .

Proposition 6. For the pricing strategy 2 of the manufacturer, retailer 1 gains higher profit than retailer 2.

Proof: From Eqs. (10) and (11), we have

$$
\begin{aligned}
T P_{21}^{r}\left(I_{21}^{*}\right)-T P_{22}^{r}\left(I_{22}^{*}\right)=\alpha & {\left[\left(p-w_{21}^{*}-s_{1}\right)-\left(p-w_{22}^{*}-s_{2}\right)\right]+} \\
& \frac{\beta^{2}}{4(1-t)}\left[\left(p-w_{21}^{*}-s_{1}\right)^{2}-\left(p-w_{22}^{*}-s_{2}\right)^{2}\right] \\
= & \left(\left(p-w_{21}^{*}-s_{1}\right)-\left(p-w_{22}^{*}-s_{2}\right)\right)\left[\alpha+\frac{\beta^{2}}{4(1-t)}\left(\left(p-w_{21}^{*}-s_{1}\right)+\right.\right. \\
& \left.\left.\left(p-w_{22}^{*}-s_{2}\right)\right)\right]
\end{aligned}
$$




$$
=\left(w_{22}^{*}-w_{21}^{*}+s_{2}-s_{1}\right)\left[\alpha+\frac{\beta^{2}}{4(1-t)}\left(\left(p-w_{21}^{*}-s_{1}\right)+\left(p-w_{22}^{*}-s_{2}\right)\right)\right]
$$

From Corollary 1 , we have $w_{22}^{*}-w_{21}^{*}+s_{2}-s_{1}=\frac{\left(s_{2}-s_{1}\right)(1-t)(\beta+\gamma)}{(2-t) \beta+2(1-t) \gamma}>0$. Also, $\left(p-w_{21}^{*}-s_{1}\right)>0$ and $\left(p-w_{22}^{*}-s_{2}\right)>0$. Hence, $T P_{21}^{r}\left(I_{21}^{*}\right)>T P_{22}^{r}\left(I_{22}^{*}\right)$. This completes the proof.

From Propositions 2 and 6, we find that retailer 1 obtains more profit than retailer 2 under both the pricing strategies 1 and 2. From Eq. (9) and Eq. (12), and from Propositions 4 and 5, the profit of the entire supply chain with manufacturer's pricing strategy 2 is given by

$$
\begin{aligned}
T P_{2}^{w} & =T P_{21}^{r}\left(I_{21}^{*}\right)+T P_{22}^{r}\left(I_{22}^{*}\right)+T P_{2}^{m}\left(w_{21}^{*}, w_{22}^{*}\right) \\
& =\left(p-c-s_{1}\right)\left(\alpha+\beta \sqrt{I_{21}^{*}}-\gamma \sqrt{I_{22}^{*}}\right)+\left(p-c-s_{2}\right)\left(\alpha+\beta \sqrt{I_{22}^{*}}-\gamma \sqrt{I_{21}^{*}}\right)-I_{21}^{*}-I_{22}^{*}
\end{aligned}
$$

\subsection{Case 3: Manufacturer's pricing strategy 3}

With manufacturer's pricing strategy 3 , the sequence of events is as follows: the manufacturer sets the wholesale price $w_{3}$ according to retailers' average sales cost $\left(s_{1}+s_{2}\right) / 2$; then the retailers observe $w_{3}$ and determine their optimal advertising expenditures according to their actual sales costs $s_{i}, i=1,2$, in accordance with Nash's equilibrium.

\subsubsection{The retailer's problem}

With the average sales cost $\left(s_{1}+s_{2}\right) / 2$, the retailer $i$ aims to determine his/her advertising expense that can maximize profit. Retailer $i^{\prime} s$ profit is given by

$$
T P_{3 i}^{r}\left(I_{3 i}\right)=\left(p-w_{3}-\frac{s_{1}+s_{2}}{2}\right)\left(\alpha+\beta \sqrt{I_{3 i}}-\gamma \sqrt{I_{3 j}}\right)-(1-t) I_{3 i}, i=1,2 \text { and } j=3-i \text {. }
$$

From Eq. (17), we have

$$
\begin{gathered}
\frac{d T P_{3 i}^{r}\left(I_{3 i}\right)}{d I_{3 i}}=\left(p-w_{3}-\frac{s_{1}+s_{2}}{2}\right) \frac{\beta}{2 \sqrt{I_{3 i}}}-(1-t) \\
\frac{d^{2} T P_{3 i}^{r}\left(I_{3 i}\right)}{d^{2} I_{3 i}}=-\left(p-w_{3}-\frac{s_{1}+s_{2}}{2}\right) \frac{\beta}{4 I_{1 i}^{3 / 2}}<0 .
\end{gathered}
$$

Therefore, $T P_{3 i}^{r}\left(I_{3 i}\right)$ is concave in $I_{3 i}$. Solving $\frac{d T P_{3 i}^{r}\left(I_{3 i}\right)}{d I_{3 i}}=0$, we get retailer's optimal advertising expenditure as

$$
I_{31}^{0}=I_{32}^{0}=\left(p-w_{3}-\frac{s_{1}+s_{2}}{2}\right) \frac{\beta^{2}}{4(1-t)^{2}} .
$$

\subsubsection{The manufacturer's problem}

The manufacturer aims to determine the wholesale price which maximizes his/her profit. The manufacturer's profit is given by

$$
T P_{3}^{m}\left(w_{3}\right)=\sum_{i=1}^{2}\left[\left(w_{3}-c\right)\left(\alpha+\beta \sqrt{I_{3 i}^{0}}-\gamma \sqrt{I_{3 j}^{0}}\right)\right]-t\left(I_{31}^{0}+I_{32}^{0}\right), j=3-i .
$$

Substituting the values of $I_{31}^{0}$ and $I_{32}^{0}$ from Eq. (18), the manufacturer's profit can be written as 


$$
T P_{3}^{m}\left(w_{3}\right)=\left(w_{3}-c\right)\left[2 \alpha+\frac{\beta(\beta-\gamma)}{2(1-t)}\left(p-w_{3}-\frac{s_{1}+s_{2}}{2}\right)\right]-\frac{t \beta^{2}}{2(1-t)^{2}}\left(p-w_{3}-\frac{s_{1}+s_{2}}{2}\right)^{2}
$$

Next, with regard to manufacturer's optimal wholesale price, we present below the following proposition:

Proposition 7. For the pricing strategy 3, the manufacturer's optimal wholesale price is given by

Proof: From Eq. (20), we have

$$
w_{3}^{*}=w_{1}^{*}=\frac{\frac{4 \alpha}{\beta}+\frac{\left(p-s_{1}\right) t \beta}{(1-t)^{2}}+\frac{\left(p-s_{2}\right) t \beta}{(1-t)^{2}}+\frac{\beta-\gamma}{1-t}\left(2(p+c)-s_{1}-s_{2}\right)}{\frac{2 t \beta}{(1-t)^{2}}+\frac{4(\beta-\gamma)}{(1-t)}}
$$

$$
\begin{aligned}
& \frac{d T P_{3}^{m}\left(w_{3}\right)}{d w_{3}}=2 \alpha+\frac{\beta(\beta-\gamma)}{(1-t)}\left[\left(p-w_{3}-\frac{s_{1}+s_{2}}{2}\right)-\left(w_{3}-c\right)\right]+\frac{t \beta^{2}}{(1-t)^{2}}\left(p-w_{3}-\frac{s_{1}+s_{2}}{2}\right) \\
& \frac{d^{2} T P_{3}^{m}}{d w_{3}^{2}}=-\frac{t \beta^{2}}{(1-t)^{2}}-\frac{2 \beta(\beta-\gamma)}{1-t}<0 .
\end{aligned}
$$

Therefore, $T P_{3}^{m}\left(w_{3}\right)$ is concave in $w_{3}$. Solving $\frac{d T P_{3}^{m}\left(w_{3}\right)}{d w_{3}}=0$, we obtain after simplification, the manufacturer's optimal wholesale price as

$$
w_{3}^{*}=w_{1}^{*}=\frac{\frac{4 \alpha}{\beta}+\frac{\left(p-s_{1}\right) t \beta}{(1-t)^{2}}+\frac{\left(p-s_{2}\right) t \beta}{(1-t)^{2}}+\frac{\beta-\gamma}{1-t}\left(2(p+c)-s_{1}-s_{2}\right)}{\frac{2 t \beta}{(1-t)^{2}}+\frac{4(\beta-\gamma)}{(1-t)}}
$$

This completes the proof.

From the above proposition, we conclude that the manufacturer's optimal wholesale price with manufacturer's pricing strategy 3 is equivalent to the case with pricing strategy 1 . This means that the retailers will have the same decisions as in the case under pricing strategy 1.

\section{Proposition 8.}

With manufacturer's pricing strategy 3, retailer i's optimal advertising expenditure is equivalent to the case with pricing strategy 1 , i.e, $I_{3 i}^{0}$ satisfies

$$
I_{31}^{0}=I_{11}^{*}=\frac{\left(p-w_{1}-s_{1}\right)^{2} \beta^{2}}{4(1-t)^{2}} \text { and } I_{32}^{0}=I_{12}^{*}=\frac{\left(p-w_{1}-s_{2}\right)^{2} \beta^{2}}{4(1-t)^{2}}
$$

Hence, we can conclude that profit of the entire supply chain with manufacturer's pricing strategy 3 is equal to that with manufacturer's pricing strategy 1 , i.e, $T P_{3}^{w}=T P_{1}^{w}$.

\section{Discussion}

In this section, we investigate the effects of manufacturer's different pricing strategies on retailers' optimal advertising expenditures and their optimal profits, manufacturer's optimal wholesale price and his/her optimal profit and also profit of the entire supply chain. 
Proposition 9. $w_{21}^{*}>w_{1}^{*}>w_{22}^{*}$ and $w_{1}^{*}=\frac{w_{21}^{*}+w_{22}^{*}}{2}$.

Proof: From Propositions 3 and 5, we have $w_{21}^{*}-w_{1}^{*}=\frac{\left(s_{2}-s_{1}\right)(\beta+\gamma(1-t))}{2(2-t) \beta+4(1-t) \gamma}>0$, so $w_{21}^{*}>w_{1}^{*}$. Also, $w_{1}^{*}-w_{22}^{*}=\frac{\left(s_{2}-s_{1}\right)(\beta+\gamma(1-t))}{2(2-t) \beta+4(1-t) \gamma}>0 . \quad$ Thus, $\quad w_{1}^{*}>w_{22}^{*} . \quad$ Therefore, $\quad w_{21}^{*}>w_{1}^{*}>w_{22}^{*}$. Since, $w_{21}^{*}-w_{1}^{*}=w_{1}^{*}-w_{22}^{*}$, we have $w_{1}^{*}=\frac{w_{21}^{*}+w_{22}^{*}}{2}$. This completes the proof.

The above proposition implies that, with pricing strategy 2 , manufacturer sets a higher wholesale price for retailer 1 and lower wholesale price for retailer 2 compared to those with pricing strategy 1 . With regard to retailer's optimal advertising expenditure, we now have the following result:

Proposition 10. $I_{21}^{*}<I_{11}^{*}, I_{12}^{*}<I_{22}^{*}$ and $\sqrt{I_{11}^{*}}+\sqrt{I_{12}^{*}}=\sqrt{I_{21}^{*}}+\sqrt{I_{22}^{*}}$

Proof. From Proposition 9, we have $w_{21}^{*}>w_{1}^{*}$ and $w_{22}^{*}<w_{1}^{*}$.

Therefore, $\left(p-w_{21}^{*}-s_{1}\right)^{2}<\left(p-w_{1}^{*}-s_{1}\right)^{2}$ and $\left(p-w_{22}^{*}-s_{2}\right)^{2}>\left(p-w_{1}^{*}-s_{2}\right)^{2}$. Therefore, from Propositions 1 and 4 , we obtain $I_{21}^{*}<I_{11}^{*}$ and $I_{12}^{*}<I_{22}^{*}$. Also, from Propositions 1 and 4 , we have $\sqrt{I_{11}^{*}}-\sqrt{I_{21}^{*}}=\frac{\beta}{2(1-t)}\left(w_{21}^{*}-w_{1}^{*}\right)>0 \quad$ and $\quad \sqrt{I_{22}^{*}}-\sqrt{I_{12}^{*}}=\frac{\beta}{2(1-t)}\left(w_{1}^{*}-w_{22}^{*}\right)>0$. Hence, from Proposition 9 we have, $\sqrt{I_{11}^{*}}-\sqrt{I_{21}^{*}}=\sqrt{I_{22}^{*}}-\sqrt{I_{12}^{*}}$ and then we have $\sqrt{I_{11}^{*}}+\sqrt{I_{12}^{*}}=\sqrt{I_{21}^{*}}+\sqrt{I_{22}^{*}}$. This completes the proof.

The above proposition implies that, with pricing strategy 2, the manufacturer sets a higher wholesale price for retailer 1 and therefore retailer 1 invests less in advertising compared to the case with pricing strategy 1 . On the other hand, in the case with pricing strategy 2, the manufacturer sets lower wholesale price for retailer 2 and thus retailer 2 takes this opportunity to incur a higher advertising expenditure than that in the case with pricing strategy 1.

Proposition 11. $T P_{2}^{m}\left(w_{21}^{*}, w_{22}^{*}\right)>T P_{1}^{m}\left(w_{1}^{*}\right)$

Proof: See Appendix.

Proposition 12. $T P_{21}^{r}\left(I_{21}^{*}\right)<T P_{11}^{r}\left(I_{11}^{*}\right)$ and $T P_{22}^{r}\left(I_{22}^{*}\right)>T P_{12}^{r}\left(I_{12}^{*}\right)$

Proof: See Appendix.

From the above proposition, we find that retailer 1 gains a lower profit from manufacturer's pricing strategy 2 than pricing strategy 1, and retailer 2 gains a higher profit from pricing strategy 2 than pricing strategy 1 . Since retailer 1's profit is negatively effected with manufacturer's pricing strategy 2 , retailer 1 would not like the manufacturer to adopt pricing strategy 2.

Proposition 13. The profit of the supply chain is higher for manufacturer's pricing strategy 1 than that for pricing strategy 2 i.e., $T P_{1}^{w}>T P_{2}^{w}$

Proof: See Appendix.

The above proposition suggests that for manufacturer's pricing strategy 1 , the profit of the supply chain as a whole is higher than that for pricing strategy 2. 
From the above results, we have the following conclusions: With pricing strategy 2 , the manufacturer will gain higher profit and retailer 1 will gain lower profit than the case with pricing strategy 1 . The manufacturer being the Stackelberg leader, dominates the supply chain, and therefore, if the sales cost information is symmetrical, then the manufacturer would adopt pricing strategy 2. However, since retailer 1's profit is adversely affected with manufacturer's pricing strategy 2, and sales cost information is, in general, business propriety information, retailer 1 would not like to share his/her sales cost information with the manufacturer. The manufacturer will then decide a wholesale price based on the average sales cost (pricing strategy 3 ). Therefore, retailer 1 will gain the same profit as in the case with pricing strategy 1 . Thus, pricing strategy 3 appears to be more reasonable and acceptable from practical point of view.

\section{Model II: Non-cooperative advertising model}

In this model, we assume that the manufacturer does not adopt co-op advertising and hence the manufacturer does not share retailer's advertising expenses. Thus, the retailers has to bear all the advertising expenditures themselves. The model, in particular, becomes a special case of Model I when $t=0$, and thus all the optimal results in this model can be obtained from Model I by substituting $t=0$. The optimal results are presented in Table 1. Since the optimal results under manufacturer's pricing strategy 3 are equivalent to those under manufacturer's pricing strategy 1, we discuss the optimal results under manufacturer's pricing strategies 1 and 2 only. With regard to relationship between manufacturer's optimal wholesale prices obtained from two models, we have the following results:

Corollary 2. $\hat{w}_{1}^{*}>w_{1}^{*}$ if $4 \alpha[(3-2 t) \beta-2(1-t) \gamma]>\beta^{2}(\beta-\gamma)\left[\left(p-c-s_{1}\right)+\left(p-c-s_{2}\right)\right]$

Proof: From Proposition 3 and Table 1, we have after simplifying

$$
\hat{w}_{1}^{*}-w_{1}^{*}=\frac{t\left(4 \alpha((3-2 t) \beta-2(1-t) \gamma)-\beta^{2}(\beta-\gamma)\left(\left(p-c-s_{1}\right)+\left(p-c-s_{2}\right)\right)\right)}{4 \beta(\beta-\gamma)((2-t) \beta-2(1-t) \gamma)}
$$

Since $\beta>\gamma$ and $(2-t) \beta>2(1-t) \gamma$,

it follows that $\hat{w}_{1}^{*}>w_{1}^{*}$ if $4 \alpha[(3-2 t) \beta-2(1-t) \gamma]>\beta^{2}(\beta-\gamma)\left[\left(p-c-s_{1}\right)+\left(p-c-s_{2}\right)\right]$. This completes the proof.

Corollary 3. (i) $\hat{w}_{21}^{*}>w_{21}^{*}$ if

$2 \alpha[(3-2 t) \beta-2(1-t) \gamma]((2-t) \beta+2(1-t) \gamma)>\beta^{2}(\beta-\gamma)\left(\left(p-c-s_{1}\right)(2-t) \beta+2\left(p-c-s_{2}\right)(1-t) \gamma\right)$

(ii) $\hat{w}_{22}^{*}>w_{22}^{*}$ if

$2 \alpha[(3-2 t) \beta-2(1-t) \gamma]((2-t) \beta+2(1-t) \gamma)>\beta^{2}(\beta-\gamma)\left(\left(p-c-s_{2}\right)(2-t) \beta+2\left(p-c-s_{1}\right)(1-t) \gamma\right)$

Proof: (i) From proposition 5 and Table 1, we have after simplifyplying

$$
\begin{aligned}
\hat{w}_{21}^{*}-w_{21}^{*}= & \frac{\mathrm{t}[2 \alpha((3-2 t) \beta-2(1-t) \gamma)((2-t) \beta+2(1-t) \gamma)]}{2 \beta(\beta-\gamma)\left((2-\mathrm{t})^{2} \beta^{2}-4(1-t)^{2} \gamma^{2}\right)} \\
& -\frac{t\left[\beta^{2}(\beta-\gamma)\left(\left(p-c-s_{1}\right)(2-t) \beta+2\left(p-c-s_{2}\right)(1-t) \gamma\right)\right]}{2 \beta(\beta-\gamma)\left((2-\mathrm{t})^{2} \beta^{2}-4(1-t)^{2} \gamma^{2}\right)}
\end{aligned}
$$

Since $(2-t) \beta>2(1-t) \gamma$, we have $\hat{w}_{21}^{*}>w_{21}^{*}$ if $2 \alpha[(3-2 t) \beta-2(1-t) \gamma]((2-t) \beta+2(1-t) \gamma)>$ 
$\beta^{2}(\beta-\gamma)\left(\left(p-c-s_{1}\right)(2-t) \beta+2\left(p-c-s_{2}\right)(1-t) \gamma\right)$

(ii) From proposition 5 and Table 1, we obtain after simplifying

$$
\begin{aligned}
\hat{w}_{22}^{*}-w_{22}^{*}= & \frac{\mathrm{t}[2 \alpha((3-2 t) \beta-2(1-t) \gamma)((2-t) \beta+2(1-t) \gamma)]}{2 \beta(\beta-\gamma)\left((2-\mathrm{t})^{2} \beta^{2}-4(1-t)^{2} \gamma^{2}\right)} \\
& -\frac{t\left[\beta^{2}(\beta-\gamma)\left(\left(p-c-s_{2}\right)(2-t) \beta+2\left(p-c-s_{1}\right)(1-t) \gamma\right)\right]}{2 \beta(\beta-\gamma)\left((2-\mathrm{t})^{2} \beta^{2}-4(1-t)^{2} \gamma^{2}\right)}
\end{aligned}
$$

Therefore, $\hat{w}_{22}^{*}>w_{22}^{*}$ if

$$
2 \alpha[(3-2 t) \beta-2(1-t) \gamma]((2-t) \beta+2(1-t) \gamma)>\beta^{2}(\beta-\gamma)\left(\left(p-c-s_{2}\right)(2-t) \beta+2\left(p-c-s_{1}\right)(1-t) \gamma\right)
$$

This completes the proof.

\begin{tabular}{|c|c|c|}
\hline Parameters & Pricing strategy 1 & Pricing strategy 2 \\
\hline $\begin{array}{l}\text { Advertising } \\
\text { expenditure }\end{array}$ & $\hat{I}_{11}^{*}=\frac{\left(p-\hat{w}_{1}^{*}-s_{1}\right)^{2} \beta^{2}}{4}$ & $\hat{I}_{21}^{*}=\frac{\left(p-\hat{w}_{21}^{*}-s_{1}\right)^{2} \beta^{2}}{4}$ \\
\hline & $\hat{I}_{12}^{*}=\frac{\left(p-\hat{w}_{1}^{*}-s_{2}\right)^{2} \beta^{2}}{4}$ & $\hat{I}_{22}^{*}=\frac{\left(p-\hat{w}_{22}^{*}-s_{2}\right)^{2} \beta^{2}}{4}$ \\
\hline $\begin{array}{l}\text { Wholesale } \\
\text { price }\end{array}$ & $\hat{w}_{1}^{*}=\frac{\alpha}{\beta(\beta-\gamma)}+\frac{p+c}{2}-\frac{s_{1}+s_{2}}{4}$ & $\hat{w}_{21}^{*}=\frac{\alpha}{\beta(\beta-\gamma)}+\frac{p+c}{2}-\frac{s_{1}}{2} \quad \hat{w}_{22}^{*}=\frac{\alpha}{\beta(\beta-\gamma)}+\frac{p+c}{2}-\frac{s_{2}}{2}$ \\
\hline $\begin{array}{l}\text { Retailers' } \\
\text { profit }\end{array}$ & $\hat{T P}_{11}^{\mathrm{r}}=\left(p-\hat{w}_{1}^{*}-s_{1}\right)\left[\alpha+\frac{\beta^{2}\left(p-\hat{w}_{1}^{*}-s_{1}\right)}{4}-\frac{\beta \gamma\left(p-\hat{w}_{1}^{*}-s_{2}\right)}{2}\right]$ & $\hat{T P}_{21}^{\mathrm{r}}=\left(p-\hat{w}_{21}^{*}-s_{1}\right)\left[\alpha+\frac{\beta^{2}\left(p-\hat{w}_{21}^{*}-s_{1}\right)}{4}-\frac{\beta \gamma\left(p-\hat{w}_{22}^{*}-s_{2}\right)}{2}\right]$ \\
\hline & $\hat{T P}_{12}^{\mathrm{r}}=\left(p-\hat{w}_{1}^{*}-s_{2}\right)\left[\alpha+\frac{\beta^{2}\left(p-\hat{w}_{1}^{*}-s_{2}\right)}{4}-\frac{\beta \gamma\left(p-\hat{w}_{1}^{*}-s_{1}\right)}{2}\right.$ & $\stackrel{\stackrel{\mathrm{TP}}{\mathrm{r}}}{22}^{\mathrm{r}}=\left(p-\hat{w}_{22}^{*}-s_{2}\right)\left[\alpha+\frac{\beta^{2}\left(p-\hat{w}_{22}^{*}-s_{2}\right)}{4}-\frac{\beta \gamma\left(p-\hat{w}_{21}^{*}-s_{1}\right)}{2}\right.$ \\
\hline $\begin{array}{l}\text { Manufacturer' } \\
\text { s profit }\end{array}$ & $\hat{T P}_{1}^{\mathrm{m}}=\left(\hat{w}_{1}^{*}-c\right)\left[2 \alpha+\beta(\beta-\gamma)\left(p-\hat{w}_{1}^{*}-\frac{s_{1}+s_{2}}{2}\right)\right]$ & $\begin{aligned} \hat{T P}_{2}^{\mathrm{m}}= & \left(\hat{w}_{21}^{*}-c\right)\left[\alpha+\frac{\beta^{2}\left(p-\hat{w}_{21}^{*}-s_{1}\right)}{2}-\frac{\beta \gamma\left(p-\hat{w}_{22}^{*}-s_{2}\right)}{2}\right] \\
& +\left(\hat{w}_{22}^{*}-c\right)\left[\alpha+\frac{\beta^{2}\left(p-\hat{w}_{22}^{*}-s_{2}\right)}{2}-\frac{\beta \gamma\left(p-\hat{w}_{21}^{*}-s_{1}\right)}{2}\right]\end{aligned}$ \\
\hline $\begin{array}{l}\text { Total channel } \\
\text { profit }\end{array}$ & $\begin{aligned} \hat{T P}_{1}^{\mathrm{w}} & =\left(p-c-s_{1}\right)\left(\alpha+\beta \sqrt{\hat{I}_{11}^{*}}-\gamma \sqrt{\hat{I}_{12}^{*}}\right) \\
& +\left(p-c-s_{2}\right)\left(\alpha+\beta \sqrt{\hat{I}_{12}^{*}}-\gamma \sqrt{\hat{I}_{11}^{*}}\right)-\hat{I}_{11}^{*}-\hat{I}_{12}^{*}\end{aligned}$ & $\begin{aligned} \hat{T P}_{2}^{\mathrm{w}} & =\left(p-c-s_{1}\right)\left(\alpha+\beta \sqrt{\hat{I}_{21}^{*}}-\gamma \sqrt{\hat{I}_{22}^{*}}\right) \\
& +\left(p-c-s_{2}\right)\left(\alpha+\beta \sqrt{\hat{I}_{22}^{*}}-\gamma \sqrt{\hat{I}_{21}^{*}}\right)-\hat{I}_{21}^{*}-\hat{I}_{22}^{*}\end{aligned}$ \\
\hline
\end{tabular}

\section{Table 1}

Optimal results when manufacturer does not adopt cooperative advertising

Proposition 14. $\left(w_{21}^{*}-w_{22}^{*}\right)-\left(\hat{w}_{21}^{*}-\hat{w}_{22}^{*}\right)=\frac{t \beta\left(s_{2}-s_{1}\right)}{2((2-t) \beta+2(1-t) \gamma)}$.

Proof: From Eqs. (24) and (25), we have

$$
\left(\hat{w}_{21}^{*}-w_{21}^{*}\right)-\left(\hat{w}_{22}^{*}-w_{22}^{*}\right)=-\frac{t \beta\left(s_{2}-s_{1}\right)}{2((2-t) \beta+2(1-t) \gamma)} .
$$

Therefore, $\left(w_{21}^{*}-w_{22}^{*}\right)-\left(\hat{w}_{21}^{*}-\hat{w}_{22}^{*}\right)=\frac{t \beta\left(s_{2}-s_{1}\right)}{2((2-t) \beta+2(1-t) \gamma)}>0$. This completes the proof. 
This proposition implies that difference between manufacturer's optimal wholesale prices under pricing strategy 2 in the cooperative advertising model is greater than that in the non-cooperative advertising model.

Corollary 4. $\sqrt{\hat{I}_{21}^{*}}+\sqrt{I_{22}^{*}}=\sqrt{I_{21}^{*}}+\sqrt{\hat{I}_{22}^{*}}+\frac{t \beta^{2}\left(s_{2}-s_{1}\right)}{4((2-t) \beta+2(1-t) \gamma)}$.

Proof: From Proposition 4 and Table 1, we have $\sqrt{\hat{I}_{22}^{*}}-\sqrt{\hat{I}_{21}^{*}}=\frac{\beta}{2}\left[\left(\hat{w}_{21}^{*}-\hat{w}_{22}^{*}\right)+\left(s_{1}-s_{2}\right)\right]$ and $\sqrt{I_{22}^{*}}-\sqrt{I_{21}^{*}}=\frac{\beta}{2}\left[\left(w_{21}^{*}-w_{22}^{*}\right)+\left(s_{1}-s_{2}\right)\right]$. Then, from Proposition 14, we have $\left(\sqrt{I_{22}^{*}}-\sqrt{I_{21}^{*}}\right)$ $-\left(\sqrt{\hat{I}_{22}^{*}}-\sqrt{\hat{I}_{21}^{*}}\right)=\frac{\beta}{2}\left[\left(w_{21}^{*}-w_{22}^{*}\right)-\left(\hat{w}_{21}^{*}-\hat{w}_{22}^{*}\right)\right]=\frac{t \beta^{2}\left(s_{2}-s_{1}\right)}{4((2-t) \beta+2(1-t) \gamma)}>0$. Rearranging the terms, we obtain the required result. This completes the proof.

\section{Numerical study}

In this section, we illustrate by a numerical example the theoretical results developed in the previous sections. The parameter-values are taken as follows: $\alpha=7, \beta=2, \gamma=0.2, p=\$ 16, c=\$ 5, s_{1}=$ $\$ 2, s_{2}=\$ 3, t=0.1$.

\section{Model I: Cooperative advertising model}

For the pricing strategy 1 of the manufacturer, the optimal results are obtained as $w_{1}^{*}=\$ 11.14, I_{11}^{*}=\$ 10.06, I_{12}^{*}=\$ 4.25, T P_{11}^{r}=\$ 27.86, T P_{12}^{r}=\$ 15.63, T P_{1}^{m}=\$ 142.48, T P_{1}^{w}=\$ 185.97$.

For the pricing strategy 2 of the manufacturer, the optimal results are obtained as $w_{21}^{*}=\$ 11.41, w_{22}^{*}=\$ 10.88, I_{21}^{*}=\$ 8.30, I_{22}^{*}=\$ 5.53, T P_{21}^{r}=\$ 24.40, T P_{22}^{r}=\$ 18.57, T P_{2}^{m}=\$ 142.84$, $T P_{2}^{w}=\$ 185.81$.

\section{Model II: Non-cooperative advertising model}

For the pricing strategy 1 of the manufacturer, the optimal results are obtained as $\hat{w}_{1}^{*}=\$ 11.19, \hat{I}_{11}^{*}=\$ 7.87, \hat{I}_{12}^{*}=\$ 3.26, \hat{T P}_{11}^{r}=\$ 26.50, \hat{T P}_{12}^{r}=\$ 14.88, \hat{T P}_{1}^{m}=\$ 138.14, \hat{T P}_{1}^{w}=\$ 179.52$. For the pricing strategy 2 of the manufacturer, the optimal results are obtained as follows: $\hat{w}_{21}^{*}=\$ 11.44, \hat{w}_{22}^{*}=\$ 10.94, \hat{I}_{21}^{*}=\$ 6.53, \hat{I}_{22}^{*}=\$ 4.22, \hat{T P}_{21}^{r}=\$ 23.37, \hat{T P}_{22}^{r}=\$ 17.56$, $\hat{T P}_{2}^{m}=\$ 138.41, \hat{T P}_{2}^{w}=\$ 179.34$.

From the numerical results of the two models, we find that retailer 1 gains a higher profit than retailer 2 under both the pricing strategies set by the manufacturer. Also, retailer 1 incurs a higher advertising expenditure than retailer 2 irrespective of the pricing strategies set by the manufacturer. We observe that retailer 1's profit is higher with pricing strategy 1 of the manufacturer than with pricing strategy 2 , whereas retailer 2's profit is higher with pricing strategy 2 than with pricing strategy 1 . The manufacturer's profit is higher with pricing strategy 2 than with pricing strategy 1 . With pricing strategy 1, profit of the entire supply chain is higher than with pricing strategy 2 . All the above 
observations are consistent with the theoretical results derived in the two models. We also find that cooperative advertising increases the profit not only for the manufacturer and the retailers but also for the entire supply chain. Thus, cooperative advertising is beneficial not only to the participating entities but also to the entire supply chain. Next, we examine the effect of competition between retailers and impact of few model-parameters on the performance of the whole chain and its members.

\subsection{The effect of competition}

The effect of competition on profit is shown in Figs. 1-2. Fig. 1 describes the impact of competition on retailers' profits under manufacturer's pricing strategies 1 and 2. From Fig. 1, we observe that retailer 1 's profit is higher than retailer 2's profit under each of the pricing strategies. At the same time, retailer 1 's profit under pricing strategy 2 is lower than that under pricing strategy 1 and retailer 2's profit is higher than that under pricing strategy 1. Fig. 2 shows that the manufacturer obtains a higher profit with pricing strategy 2 than with pricing strategy 1 . The profit of the entire supply chain is higher under pricing strategy 1 than under pricing strategy 2. From Figs. 1 and 2, we find that as competition between retailers increases, the profits of the manufacturer, retailers, and the entire supply chain decrease. Thus, increase in competition will adversely affect the manufacturer, retailers, and the supply chain. Fig. 3 shows that retailers' optimal advertising expenditure decreases with increase in competition.

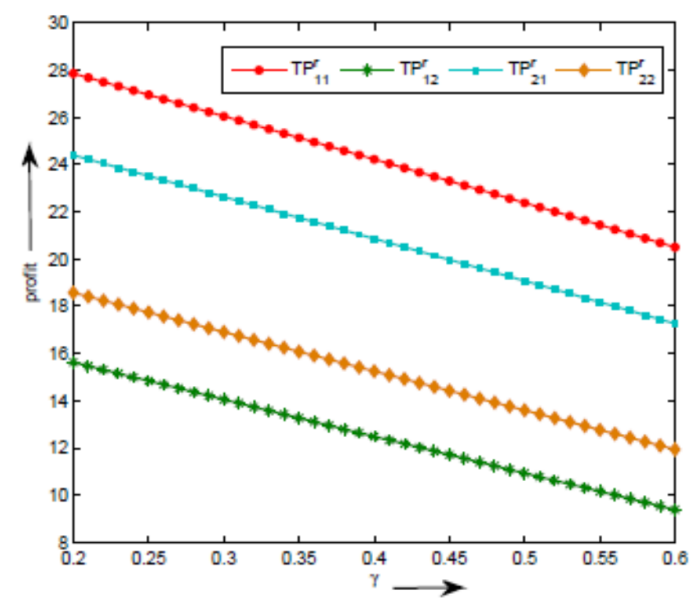

Fig. 1. Impact of competition on retailers' profit

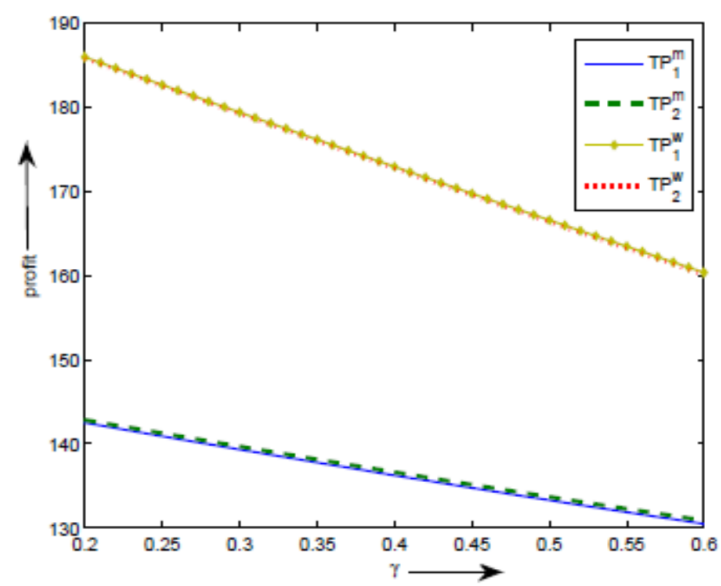

Fig. 2. Impact of competition on manufacturer'sand entire supply’s profits

\subsection{Sensitivity analysis}

In this sub-section, we perform the sensitivity analysis of key model-parameters of Model I under each of the manufacturer's pricing strategies. From Figs. 4-6, we observe that an increase in unit retail price $p$ results in increase in profits of the manufacturer, retailers and the entire supply chain.

Also, retailers' optimal advertising expenditures increase with increase in unit retail price. From Figs. 7-9, we find that the profits of the retailers, manufacturer and the entire supply chain all decrease with increase in manufacturer's unit production $\operatorname{cost} c$. Also, each retailer's optimal advertising expenditure decreases with increase in the manufacturer's unit production cost.

The above observations suggests that the retailers increase their advertising expenditure to generate more customer demand and hence order higher quantities of product, which is beneficial to both retailers and manufacturer. However, with an increase in unit manufacturing cost $c$, the manufacturer 
will charge higher wholesale price to retailers which leads to a decrease in unit sale profit of the retailers. As a result, the retailers will invest less in advertising and order lesser quantities of product from the manufacturer, which will be detrimental to the profit of the manufacturer and the retailers. From Figs. 4-9, we conclude that an increase in unit retail price $p$ will benefit the manufacturer and an increase in manufacturer's unit production cost $c$, will adversely affect the profits of the manufacturer, retailers and the entire supply chain. Figs. 10-12 indicate that, as the manufacturer's participation rate $t$ of sharing retailers' advertising cost increases, the profits of the manufacturer, retailers and the entire supply chain increase. Also, retailers' optimal advertising expenditures increase when manufacturer increases his/her proportion of sharing retailers' advertising expenses.

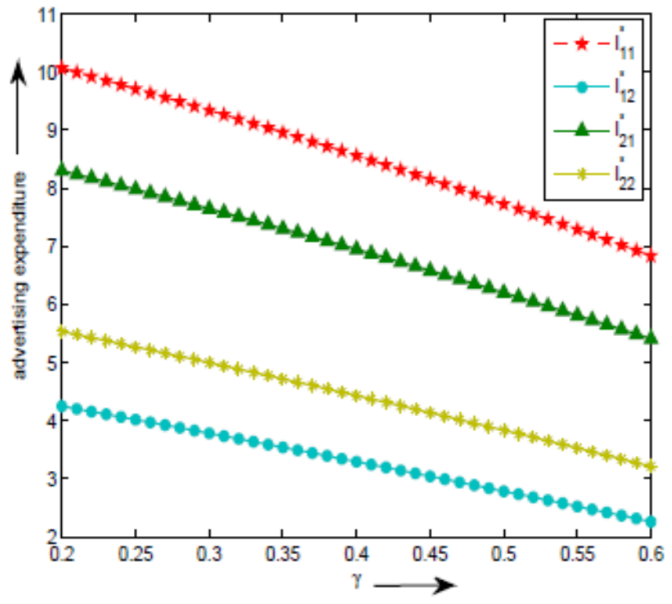

Fig. 3. Impact of competition on retailer's advertising expenditures

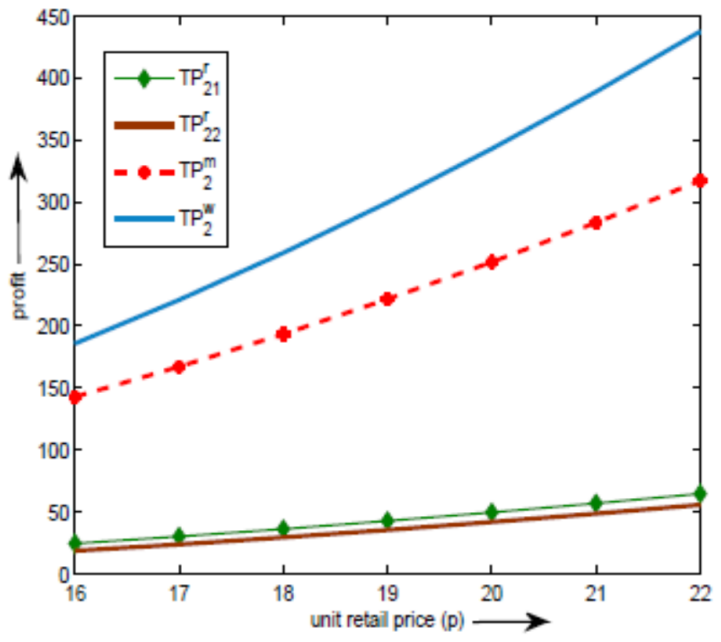

Fig. 5. Unit retail price vs. profit under pricing strategy 2

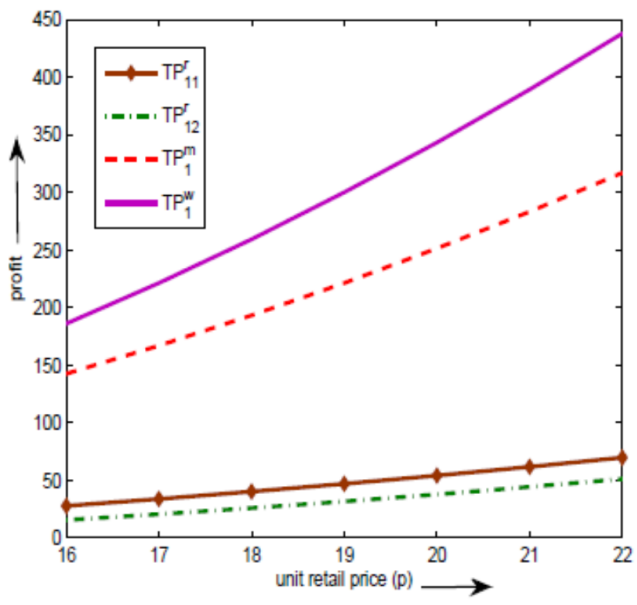

Fig. 4. Unit retail price vs. profit under pricing strategy 1

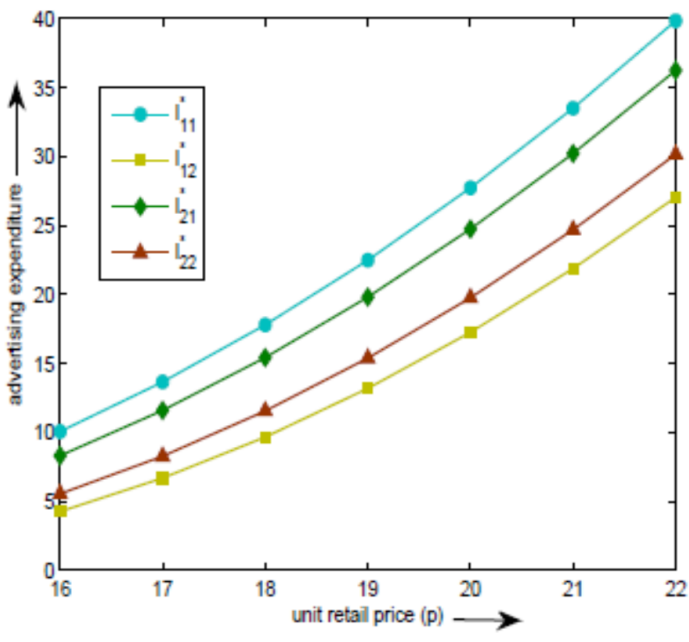

Fig. 6. Unit retail price vs. retailers' optimal advertising 


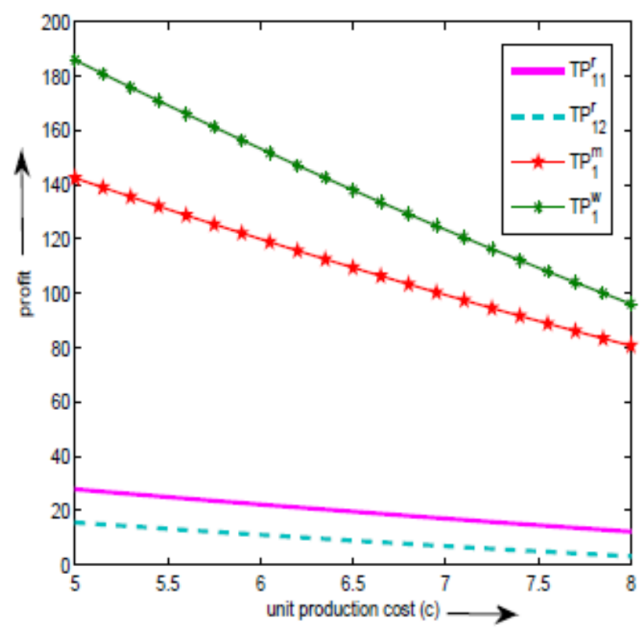

Fig. 7. Unit production cost vs. profit under pricing strategy 1

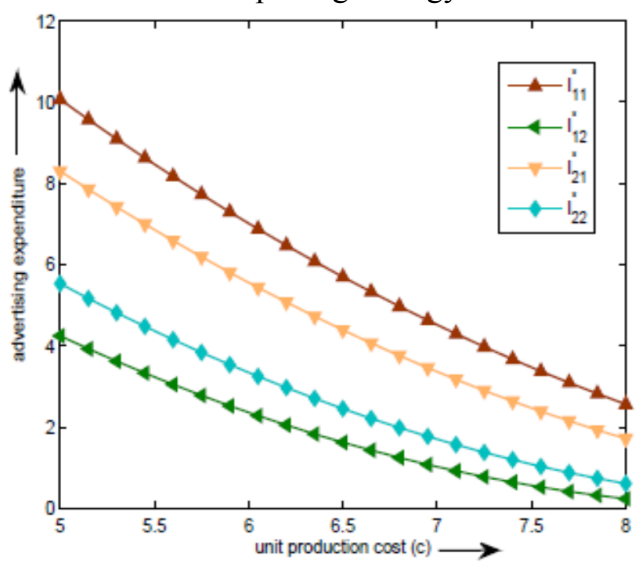

Fig. 9. Unit production cost vs. retailer's optimal advertising expenditures

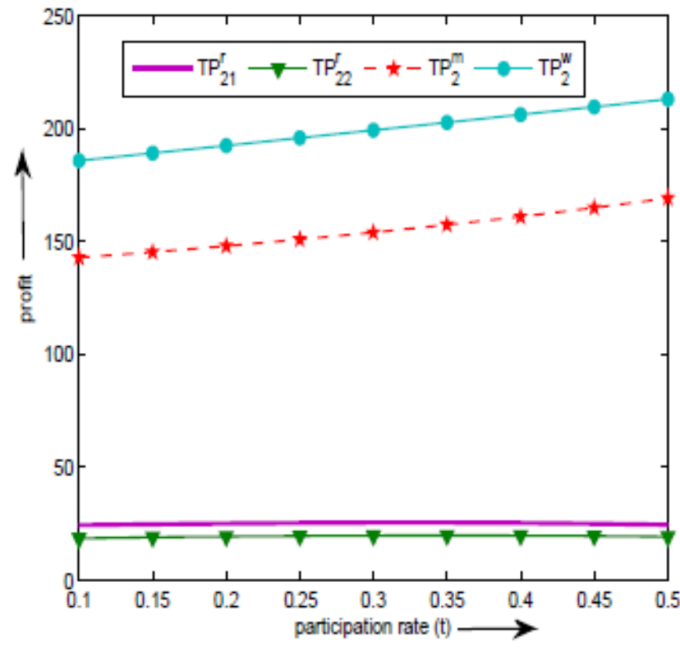

Fig. 11. Participation rate vs. profit under pricing strategy 2

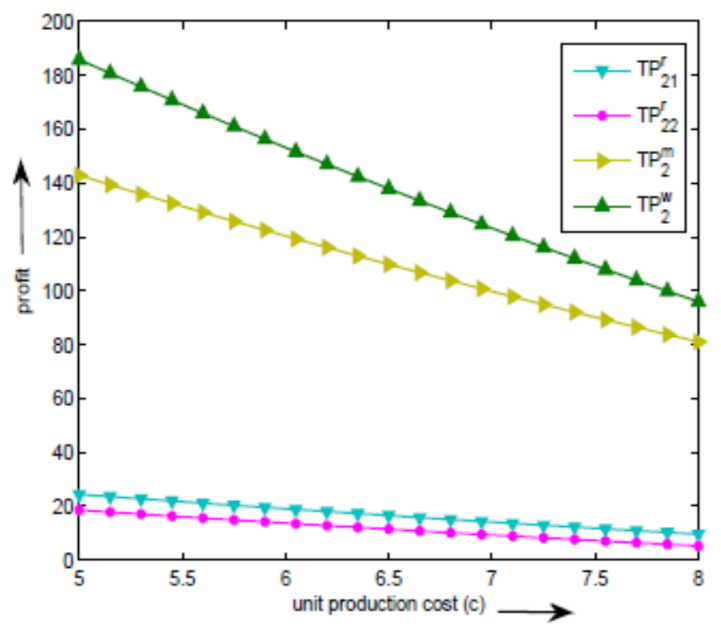

Fig. 8. Unit production cost vs. under pricing strategy 2

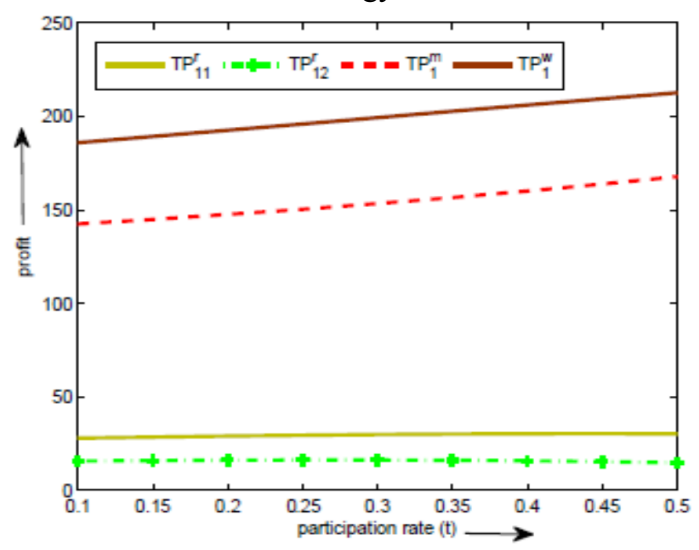

Fig. 10. Participation rate vs. profit under pricing strategy 1

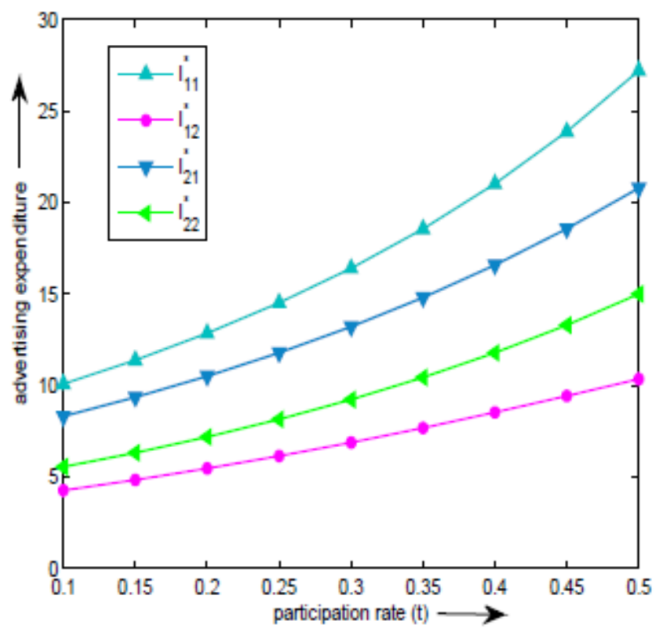

Fig. 12. Participation rate vs. retailers' optimal advertising expenditures 


\section{Conclusions}

In this paper, we have examined the effect of manufacturer's pricing strategies in a two-echelon supply chain comprising of one manufacturer and two competing retailers whose demands are sensitive to advertising investments made by them. We have developed models based on the assumption that the manufacturer does/does not undertake cooperative advertising and does/does not share a fraction of each retailer's advertising expenditure. To set wholesale price to retailers, the manufacturer as Stackelberg leader uses any one of the following three pricing strategies: (1) negotiating with retailers simultaneously and setting a wholesale price that applies to both of them; (2) negotiating with retailers separately according to their sales cost and setting different wholesale prices to the two retailers; (3) negotiating with retailers simultaneously and setting a common wholesale price for both retailers according to the average sales cost. We derive retailers' optimal advertising expenditures, their profits, manufacturer's optimal wholesale price and his/her profit and also profit of the entire supply chain. We determine which pricing strategy is beneficial to retailers, the manufacturer and the whole supply chain. We also observe that cooperative advertising is beneficial not only to the whole supply chain but also to its members. The proposed model can be extended in many ways. One immediate extension is the consideration of stochastic demand instead of deterministic demand. One may consider retailers competing in both price and advertising. The proposed model is developed assuming that one manufacturer sells through two competing retailers. It would be interesting to determine the operational strategies when more than one manufacturer also compete in addition to two competing retailers.

\section{References}

Arcelus, F.J., Kumar, S. \& Srinivasan, G. (2012). Risk tolerance and a retailer's pricing and ordering policies within a newsvendor framework. Omega - The International Journal of Management Science, 40(2), 188-198.

Aust, G., Buscher, U. (2014). Cooperative advertising models in supply chain management: A review. European Journal of Operational Research, 234, 1-14.

Berger, P.D. (1972). Vertical cooperative advertising ventures. Journal of Marketing Research, 9, 309312.

Bergen, M., \& John, G. (1997). Understanding cooperative advertising participation rates in conventional channels. Journal of Marketing Research, 34 (3), 357-369.

Brennan, L. (1988). How retailers are putting it all together? Sales and Marketing Management, 62-65. May.

Chen, X., Li, L., \& Zhou, M. (2012). Manufacturer's pricing strategy for supply chain with warranty period-dependent demand. Omega, 40, 807-816.

Dant, R., \& Berger, P. (1996). Modelling cooperative advertising decisions in franchising. Journal of the Operational Research Society, 47 (9), 1120-1136.

He, X., Krishnamoorthy, A., Prasad, A., \& Sethi, S.P. (2011). Retail competition and cooperative advertising. Operations Research Letters, 39, 11-16.

Huang, Z., \& Li, S.X., (2001). Co-operative advertising models in manufacturer-retailer supply chains: A game theory approach. European Journal of Operational Research, 135 (3), 527-544.

Huang, Z., Li, S.X., \& Mahajan, V., (2002). An analysis of manufacturer-retailer supply chain coordination in cooperative advertising. Decision sciences, 33 (3), 469-494.

Huang, Z., \& Li, S. (2005). Coordination and cooperation in manufacturer-retailer supply chains. In: Shi, Y., Xu, W., Chen, Z., et al. (Eds.), Data Mining and Knowledge Management. Springer,Berlin,pp. 174-186 (chapter 19).

Huang, J., Leng, M., \& Liang, L. (2012). Recent developments in dynamic advertising research. European Journal of Operational Research, 220, 591-609.

Hutchins, M.S. (1953). Cooperative Advertising. Roland Press, New York.

Ingene, C.A., \& Parry, M.E. (1995). Channel coordination when retailers compete. Marketing Science, 
14 (4), 360-77.

Jorgensen, S., Sigue, S.P., \& Zaccour, G. (2000). Dynamic cooperative advertising in a channel. Journal of Retailing, 76 (1), 71-92.

Jorgensen, S., \& Zaccour, G. (2003). A differential game of retailer promotions. Automatica, 39 (7), $1145-1155$.

Jorgensen, S., Taboubi, S., \& Zaccour, G. (2003). Retail promotions with negative brand image effects: is cooperation possible? European Journal of Operational Research, 150 (2), 395-405.

Karray, S., \& Zaccour, G. (2006). Could co-op advertising be a manufacturer's counter strategy to store brands? Journal of Business Research, 59 (9), 1008-1015.

Karray, S., Zaccour, G. (2007). Effectiveness of coop advertising programs in competitive distribution channels. International Game Theory Review, 9 (2), 151-167.

Kim, S.Y., \& Staelin, R. (1999). Manufacturer allowances and retailer pass-through rates in a competitive environment. Marketing Science, 18 (1), 59-76.

Kunter, M. (2012). Coordination via cost and revenue sharing in manufacturer-retailer channels. European Journal of Operational Research, 216, 477-486.

Li, S.X., Huang, Z., Zhu, J., \& Chau, P.Y.K. (2002). Cooperative advertising, game theory and manufacturer-retailer supply chains. Omega, 30, 347-357.

Mirzaee, M., Makui, A., \& Tavakoli, E. M. (2012). Supply chain coordination under retail competition and advertising dependent demand. International Journal of Industrial Engineering Computations, 3, 383-392.

Nagler, M. (2006). An exploratory analysis of the determinants of cooperative advertising participation rates. Marketing Letters, 17, 91-102.

Padmanabhan, V., \& Png, I.P.L. (1997). Manufacturers returns policies and retail competition. Marketing Science, 16 (1), 81-94.

Roslow, S., Laskey, H.A., \& Nicholls, J.A.F. (1993). The enigma of cooperative advertising. Journal of Business \& Industrial Marketing, 8, 70-79.

SeyedEsfahania, M. M., Biazaran, M., \& Gharakhani, M. (2011). A game theoretic approach to coordinate pricing and vertical co-op advertising in manufacturer-retailer supply chains. European Journal of Operational Research, 211, 263-273.

Singh, N., Vives, X. (1984). Price and quantity competition in a differentiated duopoly. Rand Journal of Economics, 15 (4),546-554.

Szmerekovsky, J.G., \& Zhang, J. (2009). Pricing and two-tier advertising with one manufacturer and one retailer. European Journal of Operational Research 192, 904-917.

Vives, X. (1984). Duopoly information equilibrium: cournot and Bertrand. Journal of Economic Theory, 34, 71-94.

Vives X., (1985). On the efficiency of Bertrand and cournot equilibria with product differentiation. Journal of Economic Theory, 36, 166-175.

Wang, S.D., Zhou, Y.W., Min, J., \& Zhong Y.G. (2011). Coordination of cooperative advertising models in a one-manufacturer two-retailer supply chain system. Computers \& Industrial Engineering, 61, 1053-1071.

Wu, C.H., Chen, C.W., \& Hsieh, C.C. (2012). Competitive pricing decisions in a two-echelon supply chain with horizontal and vertical competition. International Journal of Production Economics, 135 (1), 265-274.

Xie, J.X., \& Neyret, A. (2009). Co-op advertising and pricing models in manufacturer-retailer supply chains. Computers \& Industrial Engineering, 56, 1375-1385.

Xie, J., \& Wei, J.C. (2009). Coordinating advertising and pricing in a manufacturer-retailer channel. European Journal of Operational Research, 197, 785-791.

Yan, R. (2010). Cooperative advertising, pricing strategy and firm performance in the e-marketing age. Journal of the Academy of Marketing Science, 38 (4), 510-519.

Yue, J., Austin, J., Wang, M.C., \& Huang, Z. (2006). Coordination of cooperative advertising in a twolevel supply chain when manufacturer offers discount. European Journal of Operational Research, $168,65-85$. 


\section{Appendix}

Proof of Proposition 5. From Eq. (13), we have

$$
\begin{aligned}
& \frac{\partial T P_{2}^{m}}{\partial w_{21}}=\alpha+\frac{\beta^{2}}{2(1-t)}\left(p-w_{21}-s_{1}\right)+\frac{t\left(p-w_{21}-s_{1}\right) \beta^{2}}{2(1-t)^{2}}-\frac{\left(w_{21}-c\right) \beta^{2}}{2(1-t)} \\
& \quad-\frac{\left(p-w_{22}-s_{2}\right) \beta \gamma}{2(1-t)}+\frac{\left(w_{22}-c\right) \beta \gamma}{2(1-t)} \\
& \frac{\partial^{2} T P_{2}^{m}}{\partial w_{21}^{2}}=-\frac{\beta^{2}(2-t)}{2(1-t)^{2}}<0 \\
& \frac{\partial^{2} T P_{2}^{m}}{\partial w_{22} \partial w_{21}}=\frac{\beta \gamma}{1-t}>0 \\
& \frac{\partial T P_{2}^{m}}{\partial w_{22}}=\alpha+\frac{\beta^{2}}{2(1-t)}\left(p-w_{22}-s_{2}\right)+\frac{t\left(p-w_{22}-s_{2}\right) \beta^{2}}{2(1-t)^{2}}-\frac{\left(w_{22}-c\right) \beta^{2}}{2(1-t)} \\
& -\frac{\left(p-w_{21}-s_{1}\right) \beta \gamma}{2(1-t)}+\frac{\left(w_{21}-c\right) \beta \gamma}{2(1-t)} \\
& \frac{\partial^{2} T P_{2}^{m}}{\partial w_{22}^{2}}=-\frac{\beta^{2}(2-t)}{2(1-t)^{2}}<0
\end{aligned}
$$

The Hessian matrix is

$$
H_{1}=\left(\begin{array}{cc}
\frac{\partial^{2} T P_{2}^{m}}{\partial w_{21}^{2}} & \frac{\partial^{2} T P_{2}^{m}}{\partial w_{21} \partial w_{22}} \\
\frac{\partial^{2} T P_{2}^{m}}{\partial w_{22} \partial w_{21}} & \frac{\partial^{2} T P_{2}^{m}}{\partial w_{22}^{2}}
\end{array}\right)=\left(\begin{array}{cc}
-\frac{\beta^{2}(2-t)}{2(1-t)^{2}} & \frac{\beta \gamma}{1-t} \\
\frac{\beta \gamma}{1-t} & -\frac{\beta^{2}(2-t)}{2(1-t)^{2}}
\end{array}\right)
$$

Therefore,

$$
\begin{aligned}
\left|H_{1}\right| & =\frac{\beta^{4}(2-t)^{2}}{4(1-t)^{4}}-\frac{\beta^{2} \gamma^{2}}{(1-t)^{2}} \\
& =\frac{\beta^{2}}{4(1-t)^{4}}\left[\beta^{2}(2-t)^{2}-4 \gamma^{2}(1-t)^{2}\right]
\end{aligned}
$$

Since $\beta>\gamma$, to show that $\left|H_{1}\right|>0$, it is sufficient to show that $(2-t)^{2}>4(1-t)^{2}$, i.e., to show that $(2-t)>2(1-t)$. Since, $(2-t)-2(1-t)=t>0$ and so $\left|H_{1}\right|>0$. Therefore, $T P_{2}^{m}\left(w_{21}, w_{22}\right)$ is concave in $w_{21}$ and $w_{22}$. From Eqs. (26) and (27), we obtain, after some calculations, the values of $w_{21}^{*}$ and $w_{22}^{*}$ given in Eqs. (14) and (15), respectively. This completes the proof. 


\section{Proof of Proposition 11.}

From Eq. (4) and Eq. (12), we have

$$
\begin{aligned}
T P_{2}^{m}\left(w_{21}^{*}, w_{22}^{*}\right)-T P_{1}^{m}\left(w_{1}^{*}\right)= & \left(w_{21}^{*}-c\right)\left(\alpha+\beta \sqrt{I_{21}^{*}}-\gamma \sqrt{I_{22}^{*}}\right)+\left(w_{22}^{*}-c\right) \times \\
& \left(\alpha+\beta \sqrt{I_{22}^{*}}-\gamma \sqrt{I_{21}^{*}}\right)-\left(w_{1}^{*}-c\right)\left(\alpha+\beta \sqrt{I_{11}^{*}}-\gamma \sqrt{I_{12}^{*}}\right)- \\
& \left(w_{1}^{*}-c\right)\left(\alpha+\beta \sqrt{I_{12}^{*}}-\gamma \sqrt{I_{11}^{*}}\right)
\end{aligned}
$$

From Propositions 9 and 10, we have $w_{21}^{*}+w_{22}^{*}=2 w_{1}^{*}$ and $\sqrt{I_{11}^{*}}+\sqrt{I_{12}^{*}}=\sqrt{I_{21}^{*}}+\sqrt{I_{22}^{*}}$, respectively and so,

$T P_{2}^{m}\left(w_{21}^{*}, w_{22}^{*}\right)-T P_{1}^{m}\left(w_{1}^{*}\right)=(\beta+\gamma)\left(w_{21}^{*}-w_{1}^{*}\right)\left(\sqrt{I_{21}^{*}}-\sqrt{I_{22}^{*}}\right)$

From Propositions 3 and 5, we have $w_{21}^{*}-w_{1}^{*}=\frac{\left(s_{2}-s_{1}\right)(\beta+\gamma(1-t))}{2(2-t) \beta+4(1-t) \gamma}$ and from Proposition 4 and

Corollary 1, we have $\sqrt{I_{21}^{*}}-\sqrt{I_{22}^{*}}=\frac{\left(s_{2}-s_{1}\right) \beta(\beta+\gamma)}{2[(2-t) \beta+2(1-t) \gamma]}$.

Thus, we obtain $T P_{2}^{m}\left(w_{21}^{*}, w_{22}^{*}\right)-T P_{1}^{m}\left(w_{1}^{*}\right)=\frac{\left(s_{2}-s_{1}\right)^{2}(\beta+\gamma)^{2} \beta(\beta+\gamma(1-t))}{4[(2-t) \beta+2(1-\gamma)]^{2}}>0$. This completes the proof.

\section{Proof of Proposition 12.}

From Eqs. (1) and (9), we have

$$
\begin{aligned}
T P_{11}^{r}\left(I_{11}^{*}\right)-T P_{21}^{r}\left(I_{21}^{*}\right)= & \left(p-w_{1}^{*}-s_{1}\right)\left(\alpha+\beta \sqrt{I_{11}^{*}}-\gamma \sqrt{I_{12}^{*}}\right)-\left(p-w_{21}^{*}-s_{1}\right) \times \\
& \left(\alpha+\beta \sqrt{I_{21}^{*}}-\gamma \sqrt{I_{22}^{*}}\right)+(1-t)\left(I_{21}^{*}-I_{11}^{*}\right)
\end{aligned}
$$

From Propositions 3 and 5, we have $w_{21}^{*}=w_{1}^{*}+\frac{\left(s_{2}-s_{1}\right)(\beta+\gamma(1-t))}{2(2-t) \beta+4(1-t) \gamma}$. Then from Propositions 1,4 and 10 , we have

$$
\begin{aligned}
T P_{11}^{r}\left(I_{11}^{*}\right)-T P_{21}^{r}\left(I_{21}^{*}\right)= & \left(p-w_{1}^{*}-s_{1}\right)\left(\alpha+\beta \sqrt{I_{11}^{*}}-\gamma \sqrt{I_{12}^{*}}\right)-\left(p-w_{21}^{*}-s_{1}\right) \\
& \times\left(\alpha+\beta \sqrt{I_{21}^{*}}-\gamma \sqrt{I_{22}^{*}}\right)+\frac{(1-t) \beta^{2}}{4(1-t)^{2}}\left[\left(p-w_{21}^{*}-s_{1}\right)^{2}-\left(p-w_{1}^{*}-s_{1}\right)^{2}\right] \\
= & \left(p-w_{1}^{*}-s_{1}\right)\left(\alpha+\beta \sqrt{I_{11}^{*}}-\gamma \sqrt{I_{12}^{*}}\right)-\left(p-w_{1}^{*}-\frac{\left(s_{2}-s_{1}\right)(\beta+\gamma(1-t))}{2(2-t) \beta+4(1-t) \gamma}\right. \\
& \left.-s_{1}\right)\left(\alpha+\beta \sqrt{I_{21}^{*}}-\gamma \sqrt{I_{22}^{*}}\right)+\frac{\beta^{2}}{4(1-t)}\left[\left(2 p-w_{1}^{*}-w_{21}^{*}-2 s_{1}\right)\left(w_{1}^{*}-w_{21}^{*}\right)\right] \\
& >\left(p-w_{1}^{*}-s_{1}\right)\left(\alpha+\beta \sqrt{I_{11}^{*}}-\gamma \sqrt{I_{12}^{*}}\right)-\left(p-w_{1}^{*}-s_{1}\right)\left(\alpha+\beta \sqrt{I_{21}^{*}}-\gamma \sqrt{I_{22}^{*}}\right) \\
& -\frac{\beta^{2}}{4(1-t)}\left(w_{21}^{*}-w_{1}^{*}\right)\left(2 p-w_{1}^{*}-w_{21}^{*}-2 s_{1}\right) \\
& =\frac{\left(p-w_{1}^{*}-s_{1}\right) \beta(\beta+\gamma)\left(w_{21}^{*}-w_{1}^{*}\right)}{2(1-t)}-\frac{\beta^{2}\left(w_{21}^{*}-w_{1}^{*}\right)\left(p-w_{1}^{*}-s_{1}\right)}{2(1-t)} \\
& +\frac{\beta^{2}\left(w_{21}^{*}-w_{1}^{*}\right)^{2}}{4(1-t)} \\
&
\end{aligned}
$$




$$
\begin{aligned}
& =\frac{\beta \gamma\left(p-w_{1}^{*}-s_{1}\right)\left(w_{21}^{*}-w_{1}^{*}\right)}{2(1-t)}+\frac{\beta^{2}\left(w_{21}^{*}-w_{1}^{*}\right)^{2}}{4(1-t)} \\
& =\frac{\beta \gamma\left(p-w_{1}^{*}-s_{1}\right)\left(s_{2}-s_{1}\right)(\beta+\gamma(1-t))}{4(1-t)[(2-t) \beta+2(1-t) \gamma]} \\
& +\frac{\beta^{2}\left(s_{2}-s_{1}\right)^{2}(\beta+\gamma(1-t))^{2}}{16(1-t)[(2-t) \beta+2(1-t) \gamma]^{2}}>0
\end{aligned}
$$

Therefore, $T P_{11}^{r}\left(I_{11}^{*}\right)>T P_{21}^{r}\left(I_{21}^{*}\right)$.

From Propositions 3 and 5, we have $w_{1}^{*}=w_{22}^{*}+\frac{\left(s_{2}-s_{1}\right)(\beta+\gamma(1-t))}{2(2-t) \beta+4(1-t) \gamma}$. Then from Eqs. (1) and (9) and Propositions 1, 4 and 10, we have

$$
\begin{aligned}
T P_{22}^{r}\left(I_{22}^{*}\right)-T P_{12}^{r}\left(I_{12}^{*}\right)= & \left(p-w_{22}^{*}-s_{2}\right)\left(\alpha+\beta \sqrt{I_{22}^{*}}-\gamma \sqrt{I_{21}^{*}}\right)-\left(p-w_{1}^{*}-s_{2}\right) \\
& \times\left(\alpha+\beta \sqrt{I_{12}^{*}}-\gamma \sqrt{I_{11}^{*}}\right)+(1-t)\left(I_{12}^{*}-I_{22}^{*}\right) \\
= & \left(p-w_{22}^{*}-s_{2}\right)\left(\alpha+\beta \sqrt{I_{22}^{*}}-\gamma \sqrt{I_{21}^{*}}\right)-\left(p-w_{22}^{*}-\frac{\left(s_{2}-s_{1}\right)(\beta+\gamma(1-t))}{2(2-t) \beta+4(1-t) \gamma}\right. \\
& \left.-s_{2}\right)\left(\alpha+\beta \sqrt{I_{12}^{*}}-\gamma \sqrt{I_{11}^{*}}\right)+\frac{(1-t) \beta^{2}}{4(1-t)^{2}}\left[\left(p-w_{1}^{*}-s_{2}\right)^{2}-\left(p-w_{22}^{*}-s_{2}\right)^{2}\right] \\
> & \left(p-w_{22}^{*}-s_{2}\right)\left(\alpha+\beta \sqrt{I_{22}^{*}}-\gamma \sqrt{I_{21}^{*}}\right)-\left(p-w_{22}^{*}-s_{2}\right)\left(\alpha+\beta \sqrt{I_{12}^{*}}-\gamma \sqrt{I_{11}^{*}}\right) \\
& -\frac{\beta^{2}}{4(1-t)}\left(w_{1}^{*}-w_{22}^{*}\right)\left(2 p-w_{22}^{*}-w_{1}^{*}-2 s_{2}\right) \\
= & \frac{\left(p-w_{22}^{*}-s_{2}\right) \beta(\beta+\gamma)\left(w_{1}^{*}-w_{22}^{*}\right)}{2(1-t)}-\frac{\beta^{2}\left(p-w_{22}^{*}-s_{2}\right)\left(w_{1}^{*}-w_{22}^{*}\right)}{2(1-t)} \\
+ & \frac{\beta^{2}\left(w_{1}^{*}-w_{22}^{*}\right)^{2}}{4(1-t)} \\
& =\frac{\beta \gamma\left(p-w_{22}^{*}-s_{2}\right)\left(w_{1}^{*}-w_{22}^{*}\right)}{2(1-t)}+\frac{\beta^{2}\left(w_{1}^{*}-w_{22}^{*}\right)^{2}}{4(1-t)} \\
& =\frac{\beta \gamma\left(p-w_{22}^{*}-s_{2}\right)\left(s_{2}-s_{1}\right)(\beta+\gamma(1-t))}{4(1-t)[(2-t) \beta+2(1-t) \gamma]} \\
& +\frac{\beta^{2}\left(s_{2}-s_{1}\right)^{2}(\beta+\gamma(1-t))^{2}}{16(1-t)[(2-t) \beta+2(1-t) \gamma]^{2}}>0 \\
&
\end{aligned}
$$

Hence, $T P_{22}^{r}\left(I_{22}^{*}\right)>T P_{12}^{r}\left(I_{12}^{*}\right)$. This completes the proof.

\section{Proof of Proposition 13.}

From Propositions 1, 4, 9, 10 and Eq. (8) and Eq. (16), we have

$$
\begin{aligned}
T P_{1}^{w}-T P_{2}^{w} & =\left(p-c-s_{1}\right)\left(\alpha+\beta \sqrt{I_{11}^{*}}-\gamma \sqrt{I_{12}^{*}}\right)+\left(p-c-s_{2}\right)\left(\alpha+\beta \sqrt{I_{12}^{*}}-\gamma \sqrt{I_{11}^{*}}\right) \\
& -\left(p-c-s_{1}\right)\left(\alpha+\beta \sqrt{I_{21}^{*}}-\gamma \sqrt{I_{22}^{*}}\right)-\left(p-c-s_{2}\right)\left(\alpha+\beta \sqrt{I_{22}^{*}}-\gamma \sqrt{I_{21}^{*}}\right) \\
& +I_{21}^{*}+I_{22}^{*}-I_{11}^{*}-I_{12}^{*}
\end{aligned}
$$




$$
\begin{aligned}
& =(\beta+\gamma)\left(\sqrt{I_{11}^{*}}-\sqrt{I_{21}^{*}}\right)\left(s_{2}-s_{1}\right)+\frac{\beta^{2}}{4(1-t)^{2}}\left[\left(p-w_{22}^{*}-s_{2}\right)^{2}-\left(p-w_{1}^{*}-s_{2}\right)^{2}\right] \\
& -\frac{\beta^{2}}{4(1-t)^{2}}\left[\left(p-w_{1}^{*}-s_{1}\right)^{2}-\left(p-w_{21}^{*}-s_{1}\right)^{2}\right] \\
& =\frac{\beta(\beta+\gamma)\left(s_{2}-s_{1}\right)^{2}[\beta+\gamma(1-t)]}{4(1-t)[(2-t) \beta+2(1-t) \gamma]} \\
& -\frac{\beta^{2}\left(s_{2}-s_{1}\right)^{2}[\beta+\gamma(1-t)][(3-2 t) \beta+3(1-t) \gamma]}{8(1-t)^{2}[(2-t) \beta+2(1-t) \gamma]^{2}} \\
& >\frac{\beta(\beta+\gamma)\left(s_{2}-s_{1}\right)^{2}[\beta+\gamma(1-t)]}{4(1-t)[(2-t) \beta+2(1-t) \gamma]} \\
& -\frac{\beta^{2}\left(s_{2}-s_{1}\right)^{2}[\beta+\gamma(1-t)][(3-2 t) \beta+3(1-t) \gamma]}{8(1-t)[(2-t) \beta+2(1-t) \gamma]^{2}} \\
& =\frac{\left(s_{2}-s_{1}\right)^{2} \beta(\beta+\gamma(1-t))\left[\beta^{2}+(5-3 t) \beta \gamma+4(1-t) \gamma^{2}\right]}{8(1-t)[(2-t) \beta+2(1-t) \gamma]^{2}}>0
\end{aligned}
$$

Therefore, $T P_{1}^{w}>T P_{2}^{w}$. This completes the proof. 